\title{
Are patients with Down syndrome vulnerable to life-threatening COVID-19?
}

\author{
Harald De Cauwer ${ }^{1,2,3}\left[\right.$ Ann Spaepen ${ }^{3}$
}

Received: 6 May 2020 / Accepted: 12 May 2020 / Published online: 22 May 2020

(c) Belgian Neurological Society 2020

\begin{abstract}
Patients with Down syndrome are at increased risk of respiratory syncytial virus- and H1N1-related death. Literature on COVID-19 in Down syndrome patients is unavailable thus far. We describe the clinical course of 4 patients with Down syndrome during an outbreak of COVID-19. In all four patients, disease course was severe, warranting hospital care in three patients, with fatal outcome in one patient. Another patient receives supportive care in our institution. Our case series is the first report on probable increased risk of life-threatening disease course of COVID-19 in patients with Down syndrome. Proper surveillance, the adherence of social distancing, and the use of personal protective equipment will be essential in reducing morbidity and mortality in our patients.
\end{abstract}

Keywords Down syndrome · COVID-19 · Pneumonia · Infection · Viral disease $\cdot$ Intellectual disability

\section{Introduction}

The Respiratory syncytial virus (RSV) Gold Study showed that children with Down syndrome (DS) are at increased risk of RSV-related death [1]. During the 2009 H1N1 pandemic, a Mexican study demonstrated similar worrying figures in patients [2]. Likelihoods of hospitalization, intubation, and death were 16-fold, eightfold, and 335-fold greater, respectively, for patients with DS.

In 2020, we are confronted with the COVID-19 pandemic. Some studies report that children are less prone to COVID-19. The impact of COVID-19 on children/adults with DS has not been studied yet.

We present the clinical data of a COVID-19 cluster in our healthcare facility for patients with mental retardation.

Harald De Cauwer

harald.decauwer@ziekenhuisgeel.be

Ann Spaepen

Ann.Spaepen@MPI-Oosterlo.be

1 Department of Neurology, Dimpna Regional Hospital, AZ St Dimpna, JB Stessenstraat 2, 2440 Geel, Belgium

2 Faculty of Medicine and Health Sciences, University of Antwerp, Antwerp, Belgium

3 Medical Educational Institution, MPI Oosterlo, Geel, Belgium

\section{Case report}

In our healthcare facility for patients with mental retardation, we observed a cluster in one unit consisting of 5 DS and 17 non-DS patients: $11 / 22$ patients ( $n=4$ DS, $n=7$ non-DS) developed the clinical signs of COVID-19. Due to limited availability of test kits, COVID-19 was confirmed in only 6. Three patients with DS tested positive for COVID19 RT-PCR and had typical viral pneumonia features on CT (Figs. 1, 2).

Patient 1 (female, 60 years, DS) was hospitalized because of fever and stupor. Temperature was $37.7^{\circ} \mathrm{C}$, saturation $90 \%$, c-reactive protein $99 \mathrm{mg} / \mathrm{L}(N<5)$, d-dimer $3245 \mu \mathrm{g} / \mathrm{L}$ $(N<549)$. She was treated with oxygen, amoxicillin-clavulanic acid. Because of non-responding to the first regimen, meropenem was started with favorable outcome.

The laboratory results are summarized in Table 1.

Patient 2 (female, 48 years, DS) was admitted to hospital because of fever, coughing and dyspnea. Saturation was $83 \%$, c-reactive protein $104 \mathrm{mg} / \mathrm{L}$, d-dimer $836 \mu \mathrm{g} / \mathrm{L}$ (other laboratory results, see Table 1). She was treated with oxygen, amoxicillin-clavulanic acid, chloroquine and azithromycin and recovered.

Patient 3 (female, 55 years, DS) was admitted to hospital because of dyspnea. Temperature was $36.6{ }^{\circ} \mathrm{C}$, saturation $96 \%$, c-reactive protein $56 \mathrm{mg} / \mathrm{L}$, d-dimer $786 \mu \mathrm{g} / \mathrm{L}$ (other laboratory results, see Table 1 ). She was treated with oxygen, 


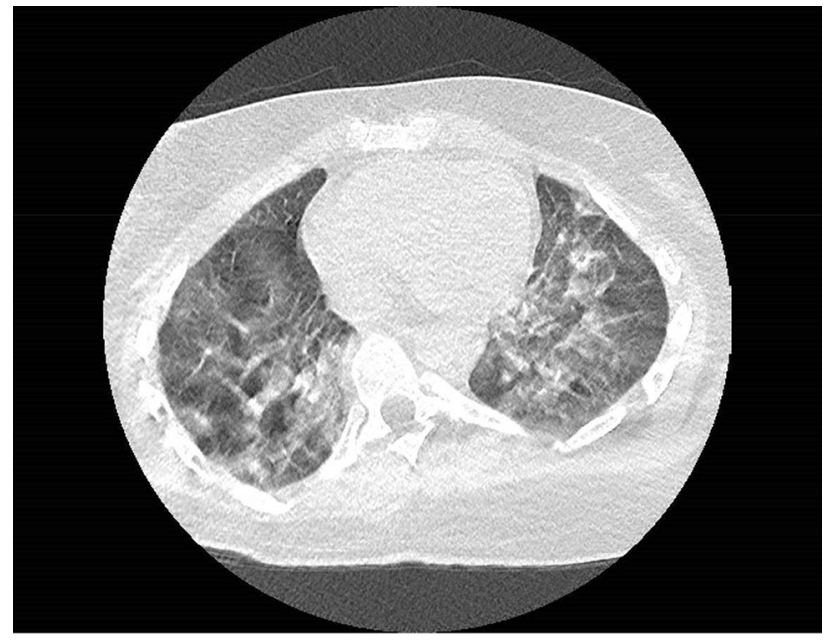

Fig. 1 Chest computed tomography scan of patient 2 showing viral pneumonitis in as much as $75 \%$ of the lungs

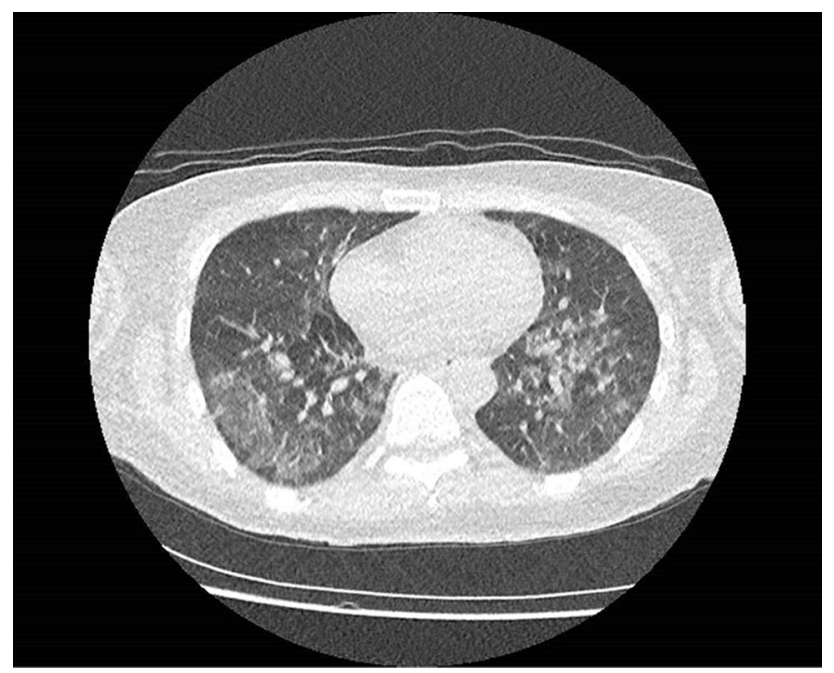

Fig. 2 Chest computed tomography scan of patient 3. 50-75\% of lungs are showing typical bilateral ground-glass opacity and pulmonary consolidation

amoxicillin-clavulanic acid, chloroquine and azithromycin, but she did not respond to therapy and died in the hospital.
Patient 4 (a female, 62 years, DS) developed respiratory failure. She was not tested, stayed in our facility and receives supportive care.

Only one male DS patient, aged 43 years, developed no signs of COVID-19.

The seven patients with non-DS showed only a mild course and recovered. Hospitalization was not warranted in them.

\section{Discussion}

In our facility for patients with intellectual disabilities, an outbreak of COVID-19 caused severe disease course only in DS patients.

We believe that immune dysregulation and increased cytokine production in DS patients make them vulnerable to infections like RSV and COVID-19 as mortality is mainly related to cytokine release syndrome [3]. Moreover, we are concerned about insufficient immunity after disease recovery, and, thus, a higher risk of reinfection. As DS patients risk inadequate immunity after vaccination, they would still be in the high-risk category despite vaccination [4].

Furthermore, we wonder what will happen when COVID19 strikes again during autumn / winter during the RSV seasonal outbreak. Will patients with RSV infection be prone to severe COVID-19 pneumonia? The effect of dual infection (RSV-COVID-19) has not been reported yet. One earlier study revealed that dual infection of SARS-metapneumovirus did not alter morbidity or death rates [5].

The recent study of Nowak et al. could be reassuring. They found less co-infections in SARS-CoV-2-infected patients (3\%) [6]. In contrast, coinfection with at least one non-SARS-CoV-2 respiratory viral pathogen was found in $13.1 \%$ of patients who tested negative for SARS-CoV-2. In patients with COVID-19-infection, non-SARS-CoV-2 coronaviridae were the most common concurrent respiratory viruses found. In contrast, in non-COVID-19 patients, the most common respiratory virus co-infections were those commonly seen circulating in the community including rhinovirus/enterovirus, influenza viruses and coronavirus NL63.

Table 1 Initial laboratory results at admission at the emergency department

\begin{tabular}{|c|c|c|c|c|c|c|c|}
\hline Patient & $\begin{array}{l}\text { C-reactive } \\
\text { Protein } \\
\mathrm{mg} / \mathrm{L} \\
N<5\end{array}$ & $\begin{array}{l}\text { WBC } \\
10^{3} / \mu \mathrm{L} \\
N 3.5-11\end{array}$ & $\begin{array}{l}\text { Lymphocytes } \\
10^{3} / \mu \mathrm{L} \\
N 1-4.8\end{array}$ & $\begin{array}{l}\text { Blood platelets } \\
10^{3} / \mu \mathrm{L} \\
N 150-400\end{array}$ & $\begin{array}{l}\mathrm{LDH} \\
\mathrm{U} / \mathrm{L} \\
N<247\end{array}$ & $\begin{array}{l}\text { d-dimer } \\
\mu \mathrm{g} / \mathrm{L} \\
N 0-549\end{array}$ & $\begin{array}{l}\text { MCV } \\
\text { fL } \\
N 80-100\end{array}$ \\
\hline 1. Female 60 years & 99 & 3.6 & 1.04 & 173 & 702 & 3245 & 99 \\
\hline 2. Female 48 years & 104 & 3.4 & 0.77 & 101 & 398 & 836 & 111 \\
\hline 3. Female 55 years & 56 & 2.0 & 0.5 & 48 & 254 & 786 & 112 \\
\hline
\end{tabular}


RSV was only found in $0.31 \%$ of COVID-19 patients, and $1.54 \%$ of non-COVID-19 patients.

In most countries, RSV season preceded the current COVID outbreak.

Therefore, it should be of great interest to continue the RSV Gold study this autumn/winter with a special emphasis on co-infection with COVID-19, in both children and adults with DS and to continue the study of Nowak during RSV season to establish if simultaneous viral infection in SARSCoV-2 patients could potentially influence disease outcomes.

In conclusion, this is the first report on probable increased risk of severe course of disease in SARS-CoV-2 infection in patients with DS suggesting additional efforts to protect this special population. Proper surveillance, the adherence of social distancing, and the use of personal protective equipment will be essential in reducing morbidity and mortality in our patients.

Acknowledgements We would like to thank our patients and their families for we learn so much from them. We will remember patient 3 when each day dawns.

Funding The authors have not declared a specific grant for this research from any funding agency in the public, commercial or not-for-profit sectors.

\section{Compliance with ethical standards}

Conflict of interest All the authors report no disclosure or conflict of interest relevant to the manuscript. All authors report no financial disclosure.

Ethical approval This manuscript does not contain any studies with human participants or animals performed by any of the authors.
Informed consent Informed consent was obtained from all individual participants included in the study.

\section{References}

1. Löwensteyn YN, Phijffer EWEM, Simons JVL, Scheltema NM, Mazur NI, Nair H, et al. (2020) Respiratory syncytial virus-related death in children with Down syndrome: the RSV GOLD study. Pediatr Infect Dis J. https://doi.org/10.1097/INF.0000000000 002666

2. Pérez-Padilla R, Fernández R, García-Sancho C, Franco-Marina F, Aburto O, López-Gatell H et al (2010) Pandemic (H1N1) 2009 virus and Down syndrome patients. Emerg Infect Dis 16(8):1312-1314

3. Zhang C, Wu Z, Li JW, Zhao H, Wang GQ (2020) The cytokine release syndrome (CRS) of severe COVID-19 and Interleukin-6 receptor (IL-6R) antagonist Tocilizumab may be the key to reduce the mortality. Int J Antimicrob Agents 29:105954

4. Kusters MA, Bok VL, Bolz WE, Huijskens EG, Peeters MF, de Vries E (2012) Influenza A/H1N1 vaccination response is inadequate in down syndrome children when the latest cut-off values are used. Pediatr Infect Dis J 31(12):1284-1285

5. Lee N, Chan PK, Yu IT, Tsoi KK, Lui G, Sung JJ et al (2007) Co-circulation of human metapneumovirus and SARS-associated coronavirus during a major nosocomial SARS outbreak in Hong Kong. J Clin Virol 40(4):333-337

6. Nowak MD, Sordillo EM, Gitman MR, Paniz Mondolfi AE (2020) Co-infection in SARS-CoV-2 infected patients: where are influenza virus and rhinovirus/enterovirus? J Med Virol. https://doi. org/10.1002/jmv.25953

Publisher's Note Springer Nature remains neutral with regard to jurisdictional claims in published maps and institutional affiliations. 